\title{
Integrating BIM with greenhouse-gas emissions in AEC: A scientometric review
}

\author{
Mengyun $\mathrm{Li}^{1}$, Kun $\mathrm{Lu}^{1,}{ }^{1,}$,Hongyu Wang ${ }^{2}$, and Sai Wang ${ }^{1}$ \\ ${ }^{1}$ Hefei University of Technology, School of Civil Engineering, Hefei 23009, China \\ 2 Peking University, College of Urban and Environmental Sciences, Beijing 100871, China
}

\begin{abstract}
More and more attention has been paid to the application of Building Information Modeling (BIM) in the field of greenhouse-gas (GHG) emissions in Architecture, Engineering and Construction (AEC). However, systematic analysis and visualization of its development trend have not been carried out. This paper combined digital statistical method and scientometrics to analyse major documents published in the Scopus database from 2008 to September 2019 and discussed the development trend, the main journals co-citation and keywords co-occurrence of this field. And then main challenges and future research were summarized by content analysis. The results show that: (1) the number of articles related to integrating BIM with GHG emissions has increased significantly in AEC, which deserves more and more scholars to study in this field; (2) top cited journals mainly focus on built environment, BIM and clean technology; (3) BIM and Life Cycle Assessment (LCA) are the mainstream issues in the calculation, analysis and decisionmaking of GHG emissions. This review provides status quo and existing main challenges of knowledge system of BIM applied to GHG emissions in AEC, and also offers inspiration for future research.
\end{abstract}

\section{Introduction}

Buildings emit a great deal of greenhouse-gas (GHG) (especially carbon emissions) in their life cycle, leading to the intensification of the greenhouse effect and becoming an immense threat to the environment and human survival[1]. Buildings consume $40 \%$ of the world's energy and produce about $30 \%$ to $40 \%$ of all GHG in the industry [1,2]. As climate change becomes more pronounced, reducing GHG emissions has become an increasingly urgent challenge for the construction industry.

According to the "Kyoto Protocol", GHG include 6 kinds of gases in total, namely $\mathrm{CO}_{2}, \mathrm{CH}_{4}, \mathrm{~N}_{2} \mathrm{O}, \mathrm{HFCs}$, PFCs and $\mathrm{SF}_{6}$ [3]. GHG emissions are measured in kilograms of carbon dioxide equivalent $\left(\mathrm{kgCO}_{2}\right.$-eq $)$ through using the global warming potential (GWP) and taking into account the individual effects of GHG $[2,3]$.

In the past three decades, the development of Building Information Modeling (BIM) has changed the traditional design format and communication mode of Architecture, Engineering and Construction (AEC) [4]. BIM is defined as a set of interrelating policies, processes and technologies that generate a systematic approach to manage the critical information for building design and project data in digital format throughout the life cycle of a building [5]. Since BIM is conducive to the calculation and analysis of GHG, many scholars have applied BIM to the emissions of GHG in AEC and achieved some progress $[1,2]$.
In view of the inevitability of low-carbon buildings development, some scholars have made reviews of lowcarbon buildings $[6,7]$. However, there is no scientific review of the application of BIM to GHG emissions in AEC. Therefore, this study used digital statistical method and scientometrics analysis to conduct a comprehensive review of existing studies related to BIM with GHG, mainly including: (1) analysis of documents outputs; (2) network of journals co-citation ; (3) network of keywords co-occurrence. The comprehensive scientific review of this paper helps researchers understand the current knowledge system of BIM applied to GHG emissions in AEC, and provides inspiration for future research.

\section{Method}

\subsection{Overall research framework}

Bibliometric/Scientometric is a kind of method used for qualitative and quantitative analysis of the influence of journals, institutions, research organizations, individuals or countries [8]. This method originated from library science and has been widely used in literature review of various research directions recently $[9,10]$. Meanwhile, the classification and clustering of the current research can help researchers obtain a deeper understanding of the knowledge system in a certain research field[11].

This paper made an in-depth study on the BIM application of GHG emissions in AEC by combining the

\footnotetext{
* Corresponding author: lukun@mail.hfut.edu.cn
} 
digital statistical method and scientometric analysis. First, this paper searched target documents on Scopus, exported data, and analyzed documents outputs by using a digital statistical method. Digital statistical can summarize an overview of research status and trends in the scientific knowledge domain. Second, data has been imported into VOSviewer software and processed for scientometric analysis. The specific research framework of this study is shown in Fig. 1.

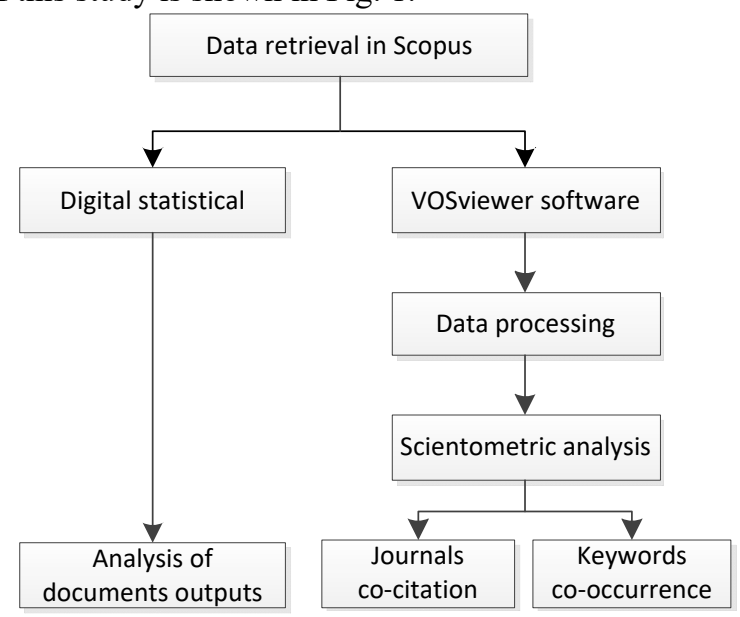

Fig. 1. Overall research framework.

\subsection{Data collection}

The data of this study come from Scopus, which is the largest abstract and citation database in the world [4]. The following retrieval code was used in the Scopus database: TITLE-ABS-KEY ("building information *model*" AND ("greenhouse gas" OR "carbon" OR "methane" OR "nitrous" OR "GHG" OR "CO2" OR "CH4" OR "N2O" OR "HFCs" OR "PFCs" OR "SF6")) AND DOCTYPE (ar OR re). Here "*" stands for fuzzy retrieval, and " TITLE-ABS-KEY " stands for title, abstract, and keyword.

It is noticeable that this paper only selected English articles for analysis, excluding book reviews and conference papers. All is for that most core journals in AEC only involve English articles [9, 10] which usually provide more comprehensive and higher quality information than other types of publications.

\subsection{Analysis tool}

The analytical tool employed in this study was VOSviewer, a software tool for building and visualizing scientometrics networks $[12,13]$. which has been used by many scholars in various fields, such as control engineering [14], interrelationships between renewable energy and agricultural economics [15], food chemistry[11]. This study adopted VOSviewer version 1.6.12 to conduct the scientometric analysis.

\section{Results and analysis}

\subsection{Analysis of documents outputs}

As of September 9, 2019, a total of 106 articles have been retrieved. Among them, the top 4 productive journals with published articles are Journal of Cleaner Production (number=13), Automation in Construction (number=8), Energy and Buildings (number=8), and Sustainability (number $=6$ ).

In terms of timing, the first journal article was published in 2008. Fig. 2 depicts the distribution of the number of annual published articles between 2008 and September 2019. As can be seen from Fig. 2, the number of published articles fluctuated from 2008 to 2019 September, while the total number increased in this period. The overall number of papers that integrating BIM with GHG emissions in AEC remains low, indicating that it is still a new area which can be studied and requires a lot of scholars to study.

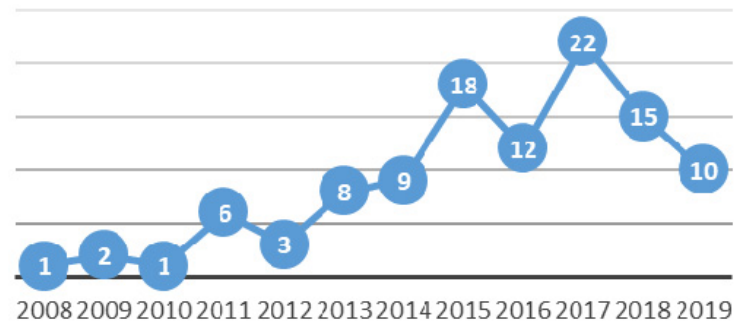

$\longrightarrow$ Number of articles

Fig. 2. Records related to articles on BIM application of GHG emissions in AEC in the Scopus database, published from January 2008 to September 2019.

\subsection{Journals co-citation network}

Autom. Constr, autom. Construct., Autom. Constr, ect., representing the same entities were merged into Automation in Construction, int j life cycle assess, int. $\mathrm{j}$. life cycle assess., ect., representing the same entities were merged into International Journal of Life Cycle Assessment, and so on. What's more, many abbreviated journal titles were expanded to full names for the convenience of researchers, such as adv. eng. inform., appl. energy, and j. comput. civ. eng.

The 106 articles were analyzed in the VOSviewer, and the network was used to detect journals with citation frequency and screen out 20 higher cited journals, as shown in Fig. 3.

The top 8 cited journals that applying BIM to GHG emissions in AEC have been shown in Table 1. There are Energy and Buildings, Building and Environment, Automation in Construction, Renewable and Sustainable 


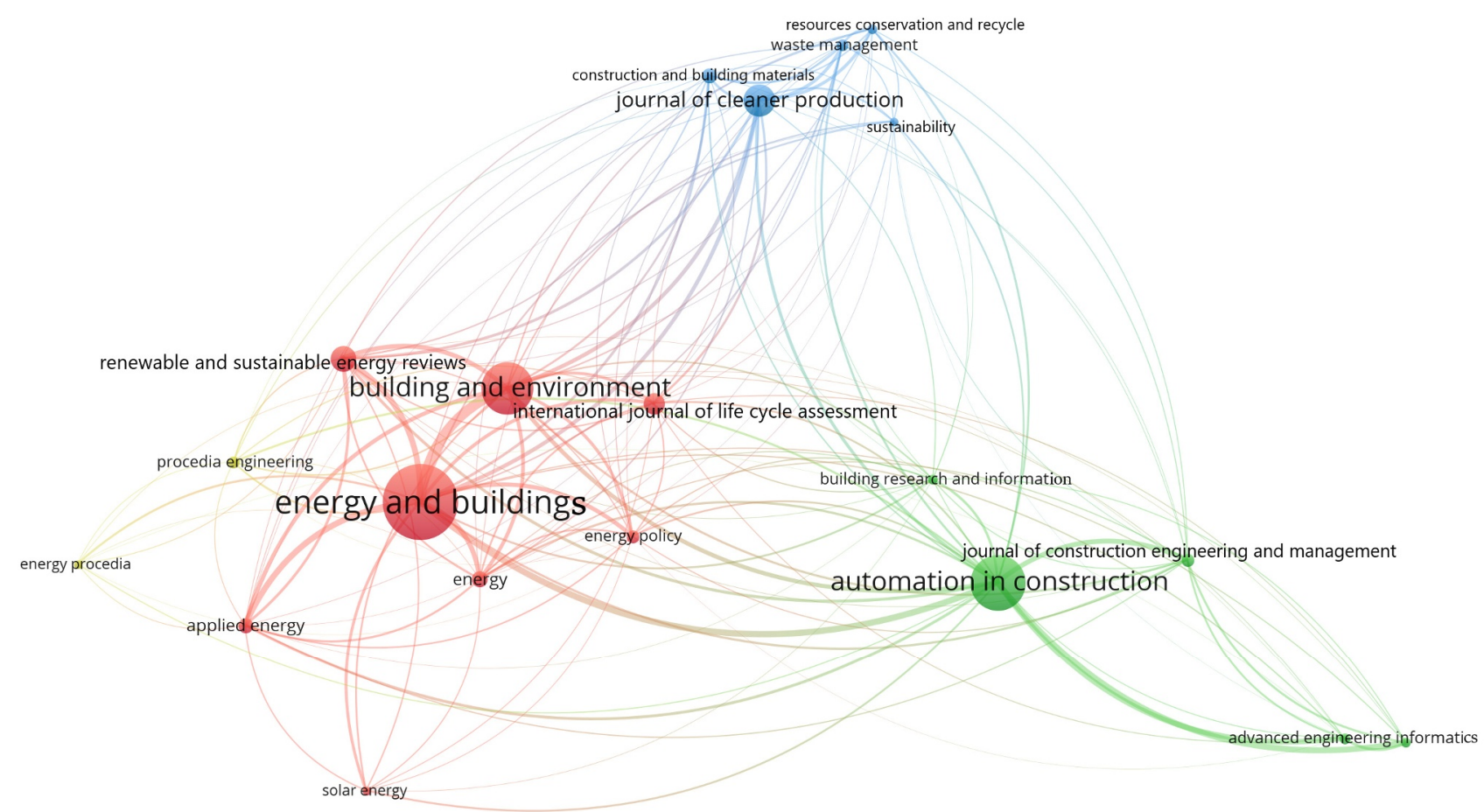

Fig. 3. Network of Co-citation journals source.

Energy Reviews, Journal of Cleaner Production, Applied Energy, Energy, Journal of Construction Engineering and Management. The top 8 journals were frequently cited by researchers in this field, which means that these journals have contributed greatly to the research on the BIM application of GHG emissions in AEC and have been recognized by researchers.

Table 1. The citations and link strength of the top 8 cited journals source.

\begin{tabular}{lcc}
\hline \multicolumn{1}{c}{ Journals } & $\begin{array}{c}\text { Citatio } \\
\text { ns }\end{array}$ & $\begin{array}{c}\text { Link } \\
\text { strength }\end{array}$ \\
\hline energy and buildings & 238 & 3492 \\
building and environment & 145 & 2506 \\
automation in construction & 157 & 2260 \\
renewable and sustainable energy & 53 & 1025 \\
reviews & 73 & 978 \\
journal of cleaner production & 27 & 872 \\
$\begin{array}{l}\text { applied energy } \\
\text { energy }\end{array}$ & 28 & 701 \\
journal of construction engineering and & 22 & 544 \\
management & & \\
\hline
\end{tabular}

In Fig. 3, node size represents the total citation frequency of each source journal. Three main branch types can be found: (1) Red branches are mainly composed of journals such as Energy and Buildings, Building Environment, which are mainly around the theme of built environment. Yellow branches beside red branche represent two conference journals, which are affiliated with Elsevier and are closely related to other journals of Elsevier; (2) Green branches include Automation in Construction, Advanced Engineering
Imformatics, Building Research and Information, etc. Articles in these categories are about the theme of BIM; (3) Blue branches are mainly constituted by Journals of Cleaner Production, Sustainability, Waste Management, etc., which concentrate on clean technology. It is not difficult to explain that articles on BIM application of GHG emissions in AEC can be submitted to journals in the three directions, namely built environment, BIM and clean technology.

\subsection{Keywords co-occurrence network}

Co-occurrence map is a knowledge map based on title and abstract field. Fig. 4 presents visualization of the most frequently keywords, which are the concise descriptions of the studied literatures. The keywords in Fig. 4 were all generated by preliminary filteration in the VOSviewer, such as Building Information Modelling, Building Information Modeling (BIM), bim and other keywords representing the same entities were combined as building information modeling, Life cycle assessment (lca), lca, life cycle assessment and other keywords representing the same entities were combined as life cycle assessment, ect.

The font and circle size corresponding to keywords represents the number that keywords appear in the research literature, and the connecting lines between keywords indicate their correlation strength. Different colors represent different clustering. As shown in Fig. 4, building information modeling, architectural design, building and life cycle assessment epitomize the mainstream topic in this field. 


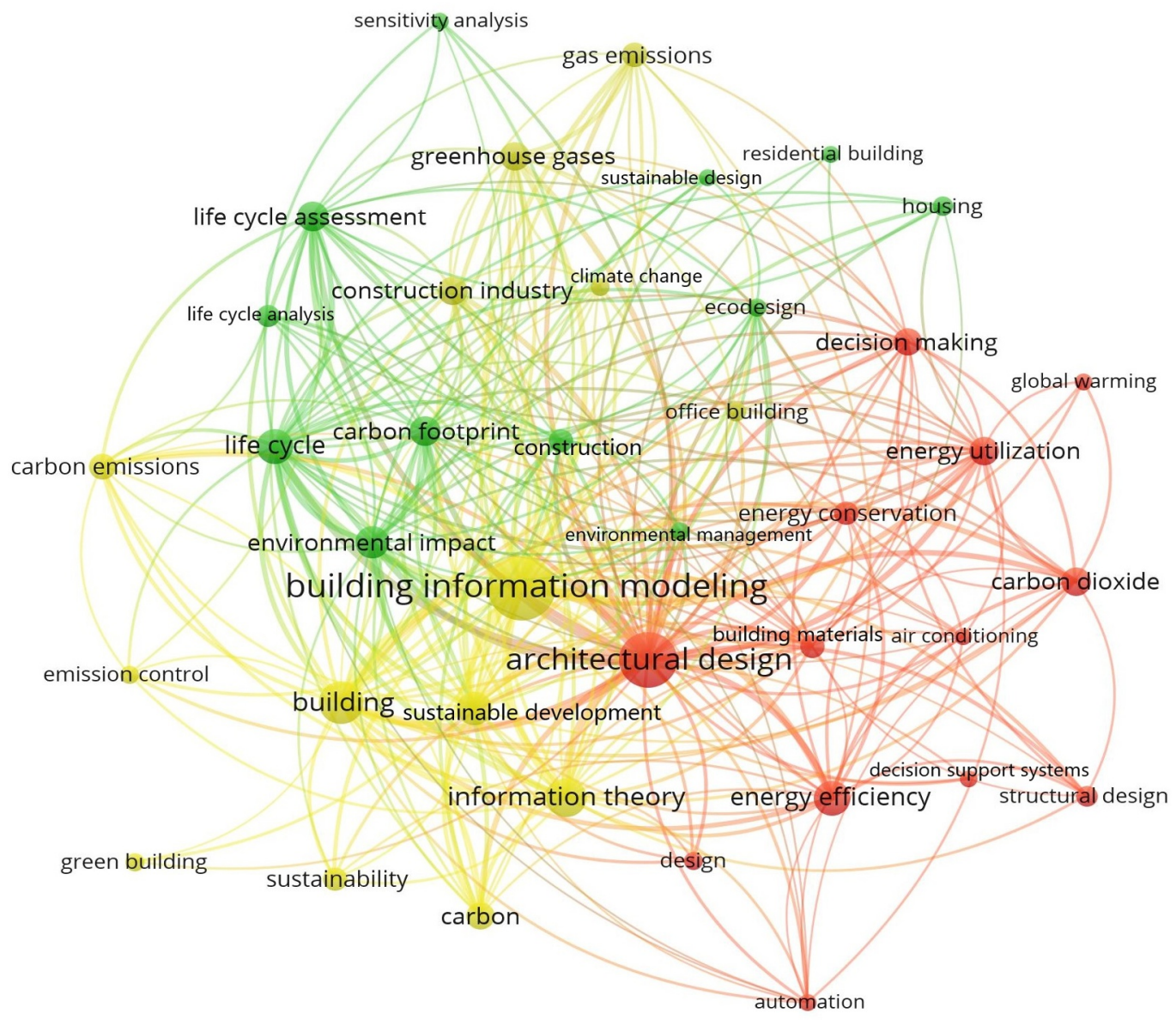

Fig. 4. Network of co-occurring keywords

According to Fig. 4, three main branches have been established. In yellow branches, the clustering focuses on building information modeling, which mainly includes greenhouse gases, carbon emissions and gas emissions, manifesting that BIM was used in the calculation and analysis of GHG and carbon emissions. In green branches, clustering places emphasis on life cycle assessment, which is closely correlated with BIM, GHG and carbon emissions, illustrating the auxiliary functions of Life Cycle Assessment (LAC). In red branches, architectural design is the centre, and it is closely connected with decision making, structural design, design support system, etc., which discloses that the ultimate purpose of applying BIM and LCA into GHG emissions is to design and make decisions.

\section{Discussion and future research}

In order to deepen readers' understanding of study on the BIM application of GHG emissions in AEC, this paper evaluated the content of 106 articles through content analysis. From these articles, the main challenges and future research directions were summarized in this field. The main challenges are: (1) information interoperability between BIM tools and sustainability tools [4]; (2) incomplete and inaccurate GHG emissions coefficient database [1]; (3) incomplete integration of BIM and LCA [16]; (4) lack of unified standards for the use of
BIM in GHG emissionds [17, 18]; (5) lack of public incentives[18].

Future research will focus on solving these problems, including: (1) solving the interactivity between BIM and GHG analysis software; (2) improving the different parts of the various building GHG emissions coefficient; (3) integrating BIM and LCA; (4) establishing unified BIM standards for GHG emissions in local; (5) government's response of applying BIM to reduce GHG emissions with certain rewards.

\section{Conclusion}

The advantages of BIM for sustainable design are obvious to all, and it has become a valuable tool for the construction, engineering and construction industry. But integrating BIM and building GHG emissions lacks a comprehensive scientific overview. This paper studies the role of BIM in AEC for GHG emissions from the perspective of scientific measurement. The evolution and development of the literature on this topic is understood through the information analysis of the literature and the content analysis of 106 journal articles published from 2008 to September 2019.

The results show that: (1) the number of published scientific works related to the application of BIM in in AEC for GHG emissions increased rapidly in the past few years, and Journal of Cleaner Production had the largest number of published works; (2) the top 8 
journals with higher citations include Energy and Building, Energy and Buildings, Building and Environment, Automation in Construction, Renewable and Sustainable Energy Reviews, Journal of Cleaner Production, Applied Energy, Energy, Journal of Construction Engineering and Management that artcles on three directions of built environment, BIM, clean technology can submit to; (3) the findings of keywords clustering can be divided into the following three clusters : (1) BIM was used mostly in the calculation and analysis of GHG emissions and carbon emissions; (2) The close relationship between LCA and BIM, GHG emissions and carbon emissions played an auxiliary role in this field. (3) BIM and LCA also were used together for GHG emissions primarily for design and decisionmaking purposes. Finally, the main challenges of this field and the development direction of future research are presented in dicussion.

Despite a thorough review in this study, the methods followed by authors have some limitations. First, Scopus database was the only search database used in the study. In addition, only peer-reviewed articles were reviewed, while books and conference papers were ignored. Finally, the 106 articles only reflected the search results of selection of keywords, which meaned that some articles may be ignored. However, the articles retrieved in this paper can cover almost all works in this field.

\section{Acknowledgement}

This paper was supported by Hefei University of Technology (2016CXCY201).

\section{References}

1. Lu, K. and H. Wang, Estimation of Building's Life Cycle Carbon Emissions Based on Life Cycle Assessment and Building Information Modeling: A Case Study of a Hospital Building in China. J. Geosci. Environ. Prot., 7(6): p. 147-165 (2019)

2. Gan, V.J.L., et al., Holistic BIM framework for sustainable low carbon design of high-rise buildings. J. Clean Prod., 195: p. 1091-1104 (2018)

3. Fenner, A.E., et al., The carbon footprint of buildings: A review of methodologies and applications. Renew. Sust. Energ. Rev., 94: p. 11421152 (2018)

4. Wong, J.K.W. and J. Zhou, Enhancing environmental sustainability over building life cycles through green BIM: A review. Autom. Constr., 57: p. 156-165 (2015)

5. Penttilä, H., Describing the changes in architectural information technology to understand design complexity and free-form architectural expression. Electron. J. Inform. Technol. Constr., 11: p. 395408 (2006)

6. Luo, T., et al., Mapping the knowledge roadmap of low carbon building: A scientometric analysis. Energy. Build., 194: p. 163-176 (2019)
7. Kesidou, S. and B.K. Sovacool, Supply chain integration for low-carbon buildings: A critical interdisciplinary review. Renew. Sust. Energ. Rev., 113: p. 109274 (2019)

8. Pritchard, A., Statistical bibliography or bibliometrics. J. Doc., 25(4): p. 348-348 (1969)

9. Zhao, X., A scientometric review of global BIM research: Analysis and visualization. Autom. Constr., 80: p. 37-47 (2017)

10. Song, J., H. Zhang, and W. Dong, A review of emerging trends in global PPP research: analysis and visualization. Scientometrics, 107(3): p. 11111147 (2016)

11. Kamdem, J.P., et al., Research trends in food chemistry: A bibliometric review of its 40 years anniversary (1976-2016). Food Chem, 294: p. 448457 (2019)

12. van Eck, N.J., et al., A Comparison of Two Techniques for Bibliometric Mapping: Multidimensional Scaling and VOS. J. Am. Soc. Inf. Sci. Technol, 61(12): p. 2405-2416 (2010)

13. van Eck, N.J. and L. Waltman, Software survey: VOSviewer, a computer program for bibliometric mapping. Scientometrics, 84(2): p. 523-538 (2010)

14. Ahmed, S. and B. Huang, Software survey: VOSviewer, a computer program for bibliometric mapping. Scientometrics, 84(2): p. 523-538 (2010)

15. Pereira Domingues Martinho, V.J., Interrelationships between renewable energy and agricultural economics: An overview. Energy Strategy Reviews. Energy Strateg. Rev., 22: p. 396409 (2018)

16. Soust-Verdaguer, B., C. Llatas, and A. GarcíaMartínez, Critical review of bim-based LCA method to buildings. Energy. Build.,. 136: p. 110-120 (2017)

17. Ansah, M.K., et al., A review and outlook for integrated BIM application in green building assessment. Sust. Cities Soc.,48: p. 101576 (2019)

18. Santos, R., et al., Informetric analysis and review of literature on the role of BIM in sustainable construction. Autom. Constr., 103: p. 221-234 (2019) 